\title{
Research Paper: Executive Function and Attention Deficits in Post-Traumatic Stress Disorder: A Study on Iranian War Veterans
}

Rajab Samadi ${ }^{1}$, Emran Mohammad Razaghi Kashani ${ }^{1}$, Maryam Kami ${ }^{2}$, Omid Rezaei ${ }^{3 *} \mathbb{D}$

1. Department of Psychiatry, Roozbeh Hospital, Tehran University of Medical Sciences, Tehran, Iran.

2. Department of Clinical Psychology, University of Social Welfare and Rehabilitation Sciences, Tehran, Iran.

3. Psychosis Research Center, Department of Psychiatry, University of Social Welfare and Rehabilitation Sciences, Tehran, Iran

Article info:

Received: 05 Oct. 2017

Accepted: 01 Jan. 2018

\section{Keywords:}

PTSD, Disabled veteran, Executive functions, Attention

\section{ABSTRACT}

Objectives: Patients with Post-Traumatic Stress Disorder (PTSD) show poor cognitive performance during neuropsychological tests. Literature is scarce regarding veterans suffering with chronic PTSD. Therefore, in this study, we aimed to compare the cognitive deficiencies of veterans with chronic PTSD with those of healthy participants.

Methods: A total of 51 hospitalized veterans and 45 healthy individuals were selected using a purposeful sampling method. Both groups performed a simple Stroop Test and the Continuous Performance Test (CPT) and completed the PTSD Checklist for DSM-5 (PCL-5).

Results: The results of independent samples t-test showed a significant difference in cognitive impairment between the veterans with PTSD and healthy subjects, and the veterans had lower performances on most aspects of the tests than that of the control group.

Discussion: According to our results, veterans with chronic PTSD showed lower cognitive performance than that of healthy individuals. This suggests that examination of the cognitive functioning of patients with PTSD can be useful in the diagnosis, prognosis, and treatment of PTSD.

\section{Introduction}

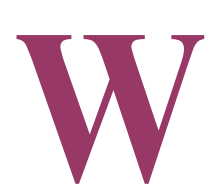

ar is a severe stressor, and people who are directly or indirectly involved with it, can experience a wide range of personal, financial, social, and cultural consequences, and more importantly, it affects their psychological functions [1]. Among the psychological consequences, Post-Traumatic Stress Disorder (PTSD) is the most common. Patients with PTSD experience a group of symptoms, such as hyperarousal, re-experiencing, avoidance, and numbness after experiencing a traumatic event; patients with PTSD respond to these kind of experiences with fear and

* Corresponding Author:

Omid Rezaei, $M D$

Address: Psychosis Research Center, Department of Psychiatry, University of Social Welfare and Rehabilitation Sciences, Tehran, Iran.

Tel: +98 (21) 33416084

E-mail: om.rezaei@uswrac.ir 
helplessness [2]. PTSD is very common among the veterans and may severely decrease their career functioning and may cause problems such as disablement; financial difficulties; physical disorders; psychological disorders, such as depression and addiction; serious problems in the family and social relationships; as well as may cause various problems to their partner and children [3]. In Iran, a national study $(\mathrm{n}=25180)$ estimated the prevalence of PTSD in the general population and found that less than $1 \%$ of the people in their society experience PTSD. However, the prevalence of PTSD among those directly affected by the Iran-Iraq war ranged from 33\% to $59 \%$ [4]. Following the Iran-Iraq war, many studies have been conducted on the prevalence and psychopathology of PTSD among veterans and their families, but researchers are currently focusing on identifying the causes of PTSD so that they can develop effective and efficient treatments for this condition [5].

Neurological approaches can provide insight into the factors responsible for protective role and risk factors that cause PTSD through the assessment of cognitive functions prior to the trauma and following the trauma [6]. Some studies have focused on the role of frontal lobe, an area of the brain that controls the executive functions, whose impairment leads to executive dysfunction [7]. Among the cognitive impairments related to PTSD, executive dysfunction is particularly associated with negative effects on work, daily life activities, social interactions, and also some symptoms of PTSD, such as avoidance and re-experiencing the trauma [8].

Executive functioning, as a theoretical construct, heavily contributes to the identification of the psychopathology of many disorders, including schizophrenia and Attention Deficit Hyperactivity Disorder (ADHD). It allows the linking of brain structures, especially the prefrontal region to psychological functions, such as problem-solving, abstract thinking, and strategy changing [9]. Executive functions have an important role in cognitive flexibility and cognitive control, emotions, and actions, and are very critical for everyday life. Problems with executive functioning are related to education, work, and responsibilities, and prevent the patient from having proper relationships with their family members and the society [10].

Patients with PTSD experience difficulties with different aspects of executive functioning, such as divided attention, cognitive flexibility, attentional control, inhibition, concentration, working memory, and planning [11-14]. Symptoms of PTSD may result from their difficulty with inhibition; therefore, patients with PTSD cannot suppress their thoughts and feelings. Consequently, their attention is directly drawn to the trauma-related stimuli [15], which is due to their limited capacity for proper cognitive control [16]. Hyperarousal symptoms can also be due to the overstimulation of attention that is followed by reduced selective attention [17]. The more impairment in the executive functioning, the less likely that pharmacotherapy can have significant results, and the more obstacles in the course of treatment [18].

Most PTSD symptoms are in the category of cognitive symptoms, and patients usually suffer from cognitive impairment; therefore, some of the problems patients with PTSD experience is re-hospitalization, which can be explained by cognitive impairment [19]. As such, rehabilitation interventions may be undertaken for patients with PTSD. In addition, findings in this domain may shed some light on the role of cognitive deficiencies in the prognosis of PTSD so that those at high risk of developing PTSD could be protected against stressors.

\section{Methods}

In this study, a causal-comparative design was used. Two groups of participants were recruited, including veterans with PTSD and healthy individuals. In order to control the demographic effects, the two groups were matched for age and sex.

\section{Population, sample, and sampling method}

The statistical population included all veterans of IranIraq war with psychiatric disabilities. From this population, a total of 50 veterans with PTSD were selected using a purposeful sampling method as the study sample, and a total of 50 healthy individuals were selected from the general population as the control group. The patients were selected from the patients of the psychiatric ward of the Imam Zaman Hospital, Iran. The inclusion criteria were as follows: education level of at least primary school and proficiency in Persian. The exclusion criteria were as follows: psychotic disorders, cognitive disorder, head injury, or physical impairment that could prevent the subjects from performing the tests. The controls had a score below the cutoff point on the PTSD Checklist for DSM-5 (PCL-5) and had no history of mental disorder or mental retardation. The sample size was determined based on the sample sizes used in the previous studies in this domain.

\section{Instruments}

The instruments used to collect data include a simple Stroop Test, the Continuous Performance Test (CPT), and PCL-5. 


\section{Simple Stroop Test}

The simple Stroop Test was developed by John Ridley Stroop (1935) to assess executive functions, such as cognitive inhibition. In the computerized version of the test, a congruent word (the word' color is congruent with its meaning) and an incongruent word (the word' color is incongruent with its meaning) are randomly presented to the subject for a certain amount of time, and the reaction time, number of right and wrong responses, and also the interference score are precisely assessed for each subject. Interference effect causes the subject to be slower in naming the incongruent words compared to the congruent ones.

In this study, the computerized version of the test was used in which subjects should respond to four colored words by pressing one of four buttons, considering the color and ignoring the meaning of the words. Overall, in this test, four words (green, yellow, blue, and red) are presented for 96 times; in $50 \%$ of the cases, the presented words are congruent and in $50 \%$ of the cases the presented words are incongruent. Each stimulus is presented on the screen for $2 \mathrm{~s}$, and the time interval between presentations of the stimuli is $0.800 \mathrm{~s}$. Golden (1975) reported Cronbach's alpha values of $0.85,0.82$, and 0.73 for the single versions of the test. In addition, test-retest reliability estimates of 0.80 to 0.91 have been reported for the test [20].

\section{CPT Test}

CPT Test is used to detect deficiencies in sustained attention and inhibition [21, 22]. It includes 150 Persian numbers ranging from 1 to 9 as test stimuli among which 30 numbers are target stimuli. The time interval between presentations of two stimuli is $500 \mathrm{~ms}$, and each stimulus is presented for $150 \mathrm{~ms}$. The subject is asked to respond to the target stimulus (selected by the examiner from 1 to 9) and press the space button on a computer keyboard. Four stimuli were selected in this study. Following are the variables assessed in this test: 1. omission error (failure to press the button when the target appears); 2 . commission error (pressing the bottom for a nontarget stimulus); and 3. reaction time (the mean reaction time [millisecond] for the correct responses). Hasani and Hadianfard reported test-retest reliability estimates of 0.90 to 0.93 for the test $(\mathrm{P}<0.001)$.

\section{PCL-5 Checklist}

PCL-5 is a 20-item checklist used to assess symptoms of PTSD. It has four subscales each assessing a cluster of symptoms for PTSD in DSM-V: intruding thoughts and memories about the trauma ( 5 items), avoidance ( 2 items), negative changes in the cognition and mood (7 items), and changes in the arousal and reactivity level (6 items) $[23,24]$. All items are rated on 4-point Likert-type scale ranging from 0 to 4 . All items assess the respondent's psychological status during the past 5 months following a particular trauma. Seven et al. found a Cronbach's alpha of 0.94 , a test-retest reliability of 0.82 , convergent validities from 0.74 to 0.85 , and discriminant validities from 0.31 to 0.60 for the PCL-5; overall, they reported acceptable psychometric properties for the checklist.

\section{Procedure}

In this study, participants were selected from the patients of the psychiatric ward of the Imam Zaman Hospital, Iran, who had received a diagnosis of PTSD according to DSM-V criteria from a psychiatrist. The control group were selected from the general population and based on the inclusion and exclusion criteria. The control group was screened using the PCL-5, and those who scored above the cutoff point on the PCL-5 were excluded from the study. In addition, five individuals among the control group who had given incomplete or suspicious answers to the PCL-5 were excluded. The examiner first provided the subjects with some information about the study objectives, the time needed for completing the tests, and ethical considerations, and then the participants were asked to voluntarily complete the consent forms. All tests were administered in one session, and the total time for presenting the tests was between 20 and $30 \mathrm{~min}$.

\section{Data analysis}

Data were analyzed using the following statistical methods: Descriptive statistics; and inferential statistics.

\section{Descriptive statistics}

Descriptive statistics, including frequencies, means, and standard deviations were used to determine demographic characteristics. The independent samples t-test was used to compare the two groups in terms of age.

\section{Inferential statistics}

The independent samples t-test was used to examine the significance level in both groups.

\section{Results}

A total of 51 veterans with PTSD and 45 individuals from the general population were included in the analysis, and the rest were excluded due to incomplete or suspicious answers. There was no significant age difference 
between the two groups $(\mathrm{t}=1.3, \mathrm{P}=0.05)$, but the level of education $\left(\chi^{2}=6, \mathrm{P}=0.01\right)$ and marital status $\left(\chi^{2}=6\right.$, $\mathrm{P}=0.001$ ) were found to be significantly higher in the control group than that of experimental group.

\section{Hypothesis 1}

Executive functioning of veterans with PTSD is impaired compared to those of healthy individuals. An independent samples t-test was used to examine the differences between the two groups in terms of executive functioning; Table 1 presents the results. Table 1 reveals that both groups had more correct responses and less reaction times for the congruent stimuli. In addition, there were significant differences between the two groups in all components except for the interference time, and the control group had a better performance than the experimental group. The difference between reaction time and number of correct responses to congruent and incongruent stimuli leads to an interference score that can be a significant predictor of cognitive inhibition as an executive function. Therefore, impairment in cognitive inhi- bition is represented by a high interference score. The interference score is significantly higher for the veterans with PTSD than that of control subjects, but there is no significant difference in the interference time.

\section{Hypothesis 2}

Sustained attention in veterans with PTSD is impaired relative to the control group. Table 2 presents the data regarding sustained attention, the means and standard deviations of commission errors, omission errors, number of correct responses, and reaction time for both groups. In addition, an independent samples t-test was used to examine the differences between the two groups in terms of sustained attention.

According to Table 2, omission error has been defined based on the mean omission score for the target stimulus, so that a respondent, who has responded to all target stimuli, will have a mean omission score of 0 . But, commission error is related to nontarget stimuli; if a respondent responds to a wrong stimulus, they have made the

Table 1. Comparison of the means scores of the experimental and control groups on the Stroop Test

\begin{tabular}{|c|c|c|c|c|c|c|c|c|}
\hline Executive Function & Group & Number & Mean & SD & $\mathbf{F}$ & df & $t$ & Sig. \\
\hline \multirow{2}{*}{$\begin{array}{l}\text { Number of errors (congru- } \\
\text { ent) }\end{array}$} & With PTSD & 51 & 4.39 & 7.26 & \multirow[b]{2}{*}{23.40} & \multirow[b]{2}{*}{51.25} & \multirow[b]{2}{*}{3.8} & \multirow[b]{2}{*}{0.001} \\
\hline & $\begin{array}{l}\text { Without } \\
\text { PTSD }\end{array}$ & 45 & 0.49 & 0.76 & & & & \\
\hline \multirow{2}{*}{$\begin{array}{l}\text { Number of errors (incongru- } \\
\text { ent) }\end{array}$} & With PTSD & 51 & 7.43 & 9.4 & \multirow[b]{2}{*}{41.009} & \multirow[b]{2}{*}{53.16} & \multirow[b]{2}{*}{4.77} & \multirow[b]{2}{*}{0.001} \\
\hline & $\begin{array}{l}\text { Without } \\
\text { PTSD }\end{array}$ & 45 & 1.05 & 1.57 & & & & \\
\hline \multirow{2}{*}{$\begin{array}{l}\text { Number of correct re- } \\
\text { sponses (congruent) }\end{array}$} & With PTSD & 51 & 37 & 11.07 & \multirow[b]{2}{*}{20.37} & \multirow[b]{2}{*}{84.83} & \multirow[b]{2}{*}{-4.83} & \multirow[b]{2}{*}{0.001} \\
\hline & $\begin{array}{l}\text { Without } \\
\text { PTSD }\end{array}$ & 45 & 45.92 & 6.72 & & & & \\
\hline \multirow{2}{*}{$\begin{array}{l}\text { Number of correct re- } \\
\text { sponses (congruent) }\end{array}$} & With PTSD & 51 & 30.55 & 13.52 & \multirow[b]{2}{*}{37.81} & \multirow[b]{2}{*}{77.41} & \multirow[b]{2}{*}{-6.61} & \multirow[b]{2}{*}{0.001} \\
\hline & $\begin{array}{l}\text { Without } \\
\text { PTSD }\end{array}$ & 45 & 44.88 & 7.08 & & & & \\
\hline \multirow{2}{*}{$\begin{array}{l}\text { Reaction time } \\
\text { (congruent) }\end{array}$} & With PTSD & 51 & 1347.59 & 232.29 & \multirow[b]{2}{*}{13.26} & \multirow[b]{2}{*}{76.08} & \multirow[b]{2}{*}{11.47} & \multirow[b]{2}{*}{0.001} \\
\hline & $\begin{array}{l}\text { Without } \\
\text { PTSD }\end{array}$ & 45 & 923.24 & 117.88 & & & & \\
\hline \multirow{2}{*}{$\begin{array}{l}\text { Reaction time } \\
\text { (congruent) }\end{array}$} & With PTSD & 51 & 1390.27 & 271.1 & \multirow[b]{2}{*}{13.99} & \multirow[b]{2}{*}{75.59} & \multirow[b]{2}{*}{9.44} & \multirow[b]{2}{*}{0.001} \\
\hline & $\begin{array}{l}\text { Without } \\
\text { PTSD }\end{array}$ & 45 & 983.86 & 135.98 & & & & \\
\hline \multirow[b]{2}{*}{ Interference score } & With PTSD & 51 & -6.45 & 8.26 & \multirow[b]{2}{*}{26.54} & \multirow[b]{2}{*}{56.34} & \multirow[b]{2}{*}{-4.53} & \multirow[b]{2}{*}{0.001} \\
\hline & $\begin{array}{l}\text { Without } \\
\text { PTSD }\end{array}$ & 45 & -1.03 & 1.96 & & & & \\
\hline \multirow[b]{2}{*}{ Interference time } & With PTSD & 51 & 42.68 & 134.6 & & & & \\
\hline & $\begin{array}{l}\text { Without } \\
\text { PTSD }\end{array}$ & 45 & 60.61 & 58.54 & 4.83 & 70.77 & -0.86 & 0.001 \\
\hline
\end{tabular}


Table 2. Comparison of the mean scores of the two groups on the CPT

\begin{tabular}{|c|c|c|c|c|c|c|c|}
\hline Variable & Group & Mean & SD & $\mathbf{F}$ & df & $\mathbf{t}$ & Sig. \\
\hline \multirow{2}{*}{ Commission error } & With PTSD & 9.27 & 17.48 & \multirow{2}{*}{26.57} & \multirow{2}{*}{50.27} & \multirow{2}{*}{3.45} & \multirow{2}{*}{0.0001} \\
\hline & Without PTSD & 0.81 & 0.85 & & & & \\
\hline \multirow{2}{*}{ Omission error } & With PTSD & 7.9 & 8.66 & \multirow{2}{*}{73.44} & \multirow{2}{*}{50.19} & \multirow{2}{*}{6.41} & \multirow{2}{*}{0.0001} \\
\hline & Without PTSD & 0.11 & 0.36 & & & & \\
\hline \multirow{2}{*}{ Number of correct answers } & With PTSD & 132.82 & 20.42 & \multirow{2}{*}{44.21} & \multirow{2}{*}{50.28} & \multirow{2}{*}{-5.67} & \multirow{2}{*}{0.0001} \\
\hline & Without PTSD & 149.07 & 1.01 & & & & \\
\hline \multirow{2}{*}{ Reaction time } & With PTSD & 1532 & 501.15 & \multirow{2}{*}{16.78} & \multirow{2}{*}{54.74} & \multirow{2}{*}{2.36} & \multirow{2}{*}{0.02} \\
\hline & Without PTSD & 1362.25 & 102.79 & & & & \\
\hline
\end{tabular}

commission error. Mean commission errors that are closer to 1 indicate higher rate of responses to nontarget stimuli. As can be seen in Table 2, there were significant differences between the two groups in all factors, and the control group had less commission and omission errors and more correct responses compared to the experimental group.

\section{Discussion}

In this study, our goal was to examine executive functioning and attention in veterans with PTSD compared to healthy individuals. The study results indicated that the experimental group had lower performance on executive functioning and attentional control than that of the control group. In the following sections, the study results will be explored in detail.

\section{Executive functioning}

A simple Stroop Test was used to assess executive functioning. Our results showed that both groups had more correct responses and less reaction times for the congruent stimuli. In addition, for all the components, except for the interference time, the experimental group had lower performance than that of the control group. The difference between reaction time and number of correct responses to congruent and incongruent stimuli creates an interference score that can be an important predictor of cognitive inhibition as an executive function.

What is important here is the overall difference between the two groups in their performance on the Stroop Test that indicated lower cognitive inhibition in veterans with PTSD than that of the control subjects. This lower performance can represent frontal lobe impairment. This finding is in line with the findings of several previous studies which showed cognitive inhibition in patients with PTSD. For example, Mirdouraghi et al. showed that patients with PTSD had deficiencies in different aspects of executive functioning. In addition, deficiency in cognitive and behavioral inhibition of those with PTSD can underlie hyperarousal, aggression, re-experiencing the trauma, and intruding thoughts that are among the major symptoms of PTSD $[25,26]$.

It seems that impairment in executive functioning is more related to the symptoms of PTSD in the cluster of numbness. Depressive symptoms moderate the relationship between PTSD and executive functioning. The more depressive symptoms the patient has, the more impairment the patients experiences in the executive functioning $[27,28]$. Stroop Test evaluates selective attention, especially the process of cognitive inhibition. Successful performance on the Stroop Test needs active section; therefore, in some cases, inhibition as an aspect of attention is important in giving a proper response. The study findings supported the hypothesis that the reported deficiencies in the overall executive functioning are partly due to the impairment in the cognitive inhibition subcomponents.

The difference between reaction time and number of correct congruent and incongruent stimuli leads to an interference score that can be an important predictor of cognitive inhibition as an executing function. Therefore, impairment in cognitive inhibition is related to a high interference score. The term executive functioning does not refer to a single cognitive ability, but includes several components, such as cognitive inhibition, cognitive flexibility, and displacement [29]. Cognitive inhibition is a process defined as "stopping or increasing a mental process in whole or in part, intentionally or unintentionally" [30]. 
Brain injury in the frontal region and also in the frontal connections with other brain regions is related to impaired performance on executive functioning tests, such as the Wisconsin Card Sorting Test (WCST) [30]. Neuroimaging studies have shown frontal lobe impairments in patients with PTSD and indicated that in these patients, abnormal activity in the prefrontal region is observed compared to healthy participants [31-33]. In another study, it was shown that participants with PTSD had more tries in the first section of the WCST (difficulty in primary problem-solving). However, other studies have also found learning problems in the performance of these patients on the WCST [34].

Consistent with the previous studies, the results of this study revealed that the veterans with PTSD had difficulties in different aspects of executive functioning, such as divided attention, cognitive flexibility, attentional control, cognitive inhibition, concentration, working memory, and planning. When performing the tests, the veterans with PTSD were unable to memorize the test instructions using their working memory to provide a proper response; they sometimes had preservation and could not inhibit their previous responses, and their attention was easily distracted from the target stimulus and was drawn to other environmental stimuli. This response pattern was found to be reflected in their mean scores on the tests. This set of cognitive impartments can reduce quality of life of patients with PTSD, and partly explain their career problems and comorbid depression.

Not paying attention to executive functions lowers the prognosis and also decreases the effectiveness of pharmacotherapy. As a comparative study on the effectiveness of pharmacotherapy in PTSD has shown, responsiveness or unresponsiveness to treatment is determined by the level of executive functioning in the person, not demographic characteristics [17]. In other words, improvement in executive functioning is regarded as a pretreatment. Given that executive functioning has different aspects, it needs to be further and more accurately investigated using different instruments and other neurological indicators.

\section{Sustained attention}

CPT was used to assess whether sustained attention was impaired in patients with PTSD. Our statistical analysis indicated that patients with PTSD were significantly different from the control subjects in all aspects except for the reaction time. In fact, control subjects had lower commission and omission errors and more correct responses than that of patients with PTSD.
The experimental group had more omission errors than that of the control group; in fact, control subjects had minor omission errors. Omission error occurs when the subject fails to press the button once seeing the stimulus. This error is related to impulsivity. Therefore, based on our results, we can conclude that patients with PTSD perform less accurately on the sustained attention task and are unable to continuously keep their attention on a specific stimulus. Neuroimaging studies have shown the activation of frontal lobe during performance on the CPT.

As was mentioned above, neuroimaging studies have shown the role of frontal lobe activity in PTSD. The impaired performance of patients with PTSD on this test could be due to the deficiencies in their alerting attention network. The alerting attention network controls the capacity to sustain a high level of consciousness and sensitivity toward incoming stimuli [35]. Vigilance is related to frontal regions and the right parietal lobe [36], and functional neuroimaging studies have shown abnormal activities in the medial frontal lobe [37]. It has also been shown in patients with PTSD that grey matter in the frontal, occipital, and parietal lobes of the brain demonstrates deficiencies [38].

In this study, despite trying to provide a standard condition for conducting the tests, different factors easily led to participants' distraction. During the tests, patients kept asking questions or looking around. Even the examiner was unable to keep them in a state of concentration. But, this problem was not seen in the control group. Given that the CPT was the first test administered, the distraction cannot be attributed to exhaustion, especially considering the fact that they had less distraction in the following tests.

\section{Conclusion}

According to the results of this study, patients with PTSD showed deficiency in some aspect of executive function and attention that may effect on the treatment procedure and caused recurrent hospitalization. In addition, we recommend further studies to examine the relationship between cognitive performance and hospitalization.

We also suggest conducting similar examinations with other Iranian PTSD populations, such as PTSD resulted from car accident or natural disasters, especially with those from other cultures, and use of advanced assessment tools, such as $\mathrm{MMRI}$ and QEEG to prevent possible biases. Future studies with patients with chronic PTSD should compare their cognitive functions with those of healthy individuals and examine the effectiveness of 
therapies based on cognitive rehabilitation in improving cognitive deficiencies, symptom alleviation, and enhancing the quality of life of combat veterans.

The study limitations are as follows: 1 . The tests were performed in the hospital environment or in the patients' homes; therefore, despite our efforts to provide a calm and noise-free condition, several factors led to patricians' distraction; 2 . Given that there were some limitations in the sampling procedure and due to the lack of control of other variables, caution should be exercised in generalizing the study results; and 3. Given the large number of questions, factors responsible for exhaustion and distraction might have influenced the ability of participants in answering the questions.

Practical suggestions of this research are: 1. Screening the cognitive deficiencies of patients with PTSD may be useful in confirming PTSD diagnosis, providing career counseling, and as guide for using cognitive rehabilitation strategies; 2. Identifying the cognitive deficiencies of patients with PTSD can contribute to a better prognosis; 3. Cognitive impairment in patients with PTSD may be the best predictor of impaired performance on different areas of daily activities, including interpersonal relationships, acquiring career skills, career success, and even therapeutic success; and 4. Cognitive rehabilitation, as a necessary intervention approach, should be included in the treatment packages for patients with PTSD.

\section{Acknowledgments}

This article was derived from the MD thesis of the corresponding author in Psychosis Research Center, University of Social Welfare and Rehabilitation Sciences, Tehran, Iran. In addition, authors wish to thank all participants and all those who helped in this project but unnamed.

\section{Conflict of Interest}

The authors declared no conflicts of interest.

\section{References}

[1] Murthy RS, Lakshminarayana R. Mental health consequencn es of war: A brief review of research findings. World Psychiatry. 2006; 5(1):25-30. PMCID: PMC1472271

[2] American Psychology Association. Diagnostic and statistical manual of mental disorders (DSM-5®). New York: American Psychology Association Pub; 2013.
[3] Sadock BJ, Sadock VA. Kaplan and Sadock's synopsis of psychiatry: Behavioral sciences/clinical psychiatry. Philadelphia: Lippincott Williams \& Wilkins; 2011.

[4] Mohammadi M-R, Davidian H, Noorbala AA, Malekafzali H, Naghavi HR, Pouretemad HR, et al. An epidemiological survey of psychiatric disorders in Iran. Clinical Practice and Epidemiology in Mental Health. 2005; 1:16. Available from: http:/ /dx.doi.org/10.1186/1745-0179-1-16

[5] Kessler RC, Sonnega A, Bromet E, Hughes M, Nelson CB. Posttraumatic stress disorder in the National Comorbidity Survey. Archives of General Psychiatry. 1995; 52(12):1048-60. Available from: http://dx.doi.org/10.1001/ archpsyc.1995.03950240066012

[6] Vasterling JJ, Brewin C. Neuropsychology of PTSD: Biological, cognitive, and clinical perspectives. New York: Guilford Press; 2005.

[7] Aupperle RL, Melrose AJ, Stein MB, Paulus MP. Executive function and PTSD: Disengaging from trauma. Neuropharmacology. 2012; 62(2):686-94. Available from: http://dx.doi. org/10.1016/j.neuropharm.2011.02.008

[8] Flaks MK, Malta SM, Almeida PP, Bueno OF, Pupo MC, Andreoli SB, et al. Attentional and executive functions are differentially affected by post-traumatic stress disorder and trauma. Journal of Psychiatric Research. 2014; 48(1):32-9. Available from: http://dx.doi.org/10.1016/j.jpsychires.2013.10.009

[9] Ghasemi N, Kiani A, Zerehposh A, Rabiei M, Vakili N. [The Study of the Differences of Attention Bias, Executive Functioning, and Reaction Time of Amphetamine Consumers in Comparison of Non Consumers (Persian)]. E'tiad Pazhoohi. 2012; 23(6):53-64

[10] Denckla, M. B. (1996). A theory and model of executive function: A neuropsychological perspective. In Lyon GR, \& Krasnegor NA editors. Attention, Memory, and Executive Function. Baltimore: Paul H Brookes Publishing.

[11] Kanagaratnam P, Asbjørnsen AE. Executive deficits in chronic PTSD related to political violence. Journal of anxiety disorders. 2007; 21(4):510-25. Available from: http://dx.doi. org/10.1016/j.janxdis.2006.06.008

[12] Koso M, Hansen S. Executive function and memory in posttraumatic stress disorder: a study of Bosnian war veterans. European Psychiatry. 2006; 21(3):167-73. Available from: http://dx.doi.org/10.1016/j.eurpsy.2005.06.004

[13] Meewisse ML, Nijdam MJ, de Vries GJ, Gersons BP, Kleber RJ, van der Velden PG, et al. Disaster-related posttraumatic stress symptoms and sustained attention: Evaluation of depressive symptomatology and sleep disturbances as mediators. Journal of Traumatic Stress. 2005; 18(4):299-302. Available from: http://dx.doi.org/10.1002/jts.20037

[14] Mehdizadeh M, Rezaei O. Third-person diagnostic interview on the cognitive insight level of psychotic patients with an insight at the denial level. Indian journal of psychological medicine. 2016; 38(3):217. Available from: http://dx.doi. org/10.4103/0253-7176.183088

[15] Brewin C, Beaton A. Thought suppression, intelligence, and working memory capacity. Behaviour Research and Therapy. 2002; 40(8):923-30. Available from: http://dx.doi. org/10.1016/s0005-7967(01)00127-9 
[16] Shiffrin RM, Schneider W. Automatic and controlled processing revisited. 1984; 91(2):269-76. PMID: 6571425

[17] McFarlane AC, Weber DL, Clark CR. Abnormal stimulus processing in posttraumatic stress disorder. Biological Psychiatry. 1993; 34(5):311-20. Available from: http://dx.doi org/10.1016/0006-3223(93)90088-u

[18] Dunkin JJ, Leuchter AF, Cook IA, Kasl-Godley JE, Abrams M, Rosenberg-Thompson S. Executive dysfunction predicts nonresponse to fluoxetine in major depression. Journal of Affective Disorders. 2000; 60(1):13-23. Available from: http:// dx.doi.org/10.1016/s0165-0327(99)00157-3

[19] Improving Attention and Managing Attentional Problems. Annals of the New York Academy of Sciences. WileyBlackwell; 2006; 931(1):359-75. Available from: http://dx.doi. org/10.1111/j.1749-6632.2001.tb05790.x

[20] Golden CJ. The Measurement of Creativity by the Stroop Color and Word Test. Journal of Personality Assessment. 1975; 39(5):502-6. Available from: http://dx.doi.org/10.1207/ s15327752jpa3905_9

[21] Gokalsing E, Robert P., Lafont V, Medecin I, Baudu C Boyer P, et al. Evaluation of the supervisory system in elderly subjects with and without disinhibition. European Psychiatry. 2000; 15(7):407-15. Available from: http:/ / dx.doi. org/10.1016/s0924-9338(00)00511-3

[22] Cornblatt B, Obuchowski M, Roberts S, Pollack S, Erlenmeyer-Kimling L. Cognitive and behavioral precursors of schizophrenia. Development and Psychopathology. 1999; 11(3):487-508. Available from: http://dx.doi.org/10.1017/ s0954579499002175

[23] Bovin MJ, Marx BP, Weathers FW, Gallagher MW, Rodriguez $\mathrm{P}$, Schnurr PP, et al. Psychometric properties of the PTSD Checklist for Diagnostic and Statistical Manual of Mental Disorders-Fifth Edition (PCL-5) in veterans. Psychological Assessment. 2016; 28(11):1379-91. Available from: http:// dx.doi.org/10.1037/pas0000254

[24] Blevins CA, Weathers FW, Davis MT, Witte TK, Domino JL. The Posttraumatic Stress Disorder Checklist forDSM5(PCL-5): Development and Initial Psychometric Evaluation. Journal of Traumatic Stress. 2015; 28(6):489-98. Available from: http://dx.doi.org/10.1002/jts.22059

[25] Mirdoraghi F, Ghanbari Hashemabadi B, Mashhadi A. [Deficiencies of Executive Functions in patients with Posttraumatic Stress Disorder (Persian)]. Iranian Journal of War and Public Health. 2012; 5(1):27-35.

[26] Mirdoraghi F, Hashemabady G, Mashhadi A. [Cognitive and behavioral inhibition in veterans with-and without post traumatic stress disorder (Persian)]. Journal of Military Medicine. 2012; 14(1):41-7.

[27] Olff M, Polak AR, Witteveen AB, Denys D. Executive function in posttraumatic stress disorder (PTSD) and the influence of comorbid depression. Neurobiology of Learning and Memory. 2014; 112:114-21. Available from: http://dx.doi. org/10.1016/j.nlm.2014.01.003

[28] Mehdizadeh M, Rezaei O, Dolatshahi B. Determining the effectiveness of the third person interview in the level of insight psychotic patients. Psychiatry research. 2016; 245:238-42. Available from: http://dx.doi.org/10.1016/j.psychres.2016.08.001
[29] Jurado MB, Rosselli M. The Elusive Nature of Executive Functions: A Review of our Current Understanding. Neuropsychology Review. 2007; 17(3):213-33. Available from: http:/ /dx.doi.org/10.1007/s11065-007-9040-z

[30] Lezak MD. Neuropsychological assessment. Oxford: Oxford University Press; 2004.

[31] Shin LM, Rauch SL, Pitman RK. Amygdala, Medial Prefrontal Cortex, and Hippocampal Function in PTSD. Annals of the New York Academy of Sciences. 2006; 1071(1):67-79. Available from: http:/ /dx.doi.org/10.1196/annals.1364.007

[32] Matsuo K, Taneichi K, Matsumoto A, Ohtani T, Yamasue $\mathrm{H}$, Sakano $\mathrm{Y}$, et al. Hypoactivation of the prefrontal cortex during verbal fluency test in PTSD: A near-infrared spectroscopy study. Psychiatry Research: Neuroimaging. 2003; 124(1):1-10. Available from: http://dx.doi.org/10.1016/ s0925-4927(03)00093-3

[33] Polak AR, Witteveen AB, Reitsma JB, Olff M. The role of executive function in posttraumatic stress disorder: A systematic review. Journal of Affective Disorders. 2012; 141(1):11-21. Available from: http://dx.doi.org/10.1016/j.jad.2012.01.001

[34] Twamley EW, Allard CB, Thorp SR, Norman SB, Cissell SH, Berardi KH, et al. Cognitive impairment and functioning in PTSD related to intimate partner violence. Journal of the International Neuropsychological Society. 2009; 15(06):879. Available from: http://dx.doi.org/10.1017/ s135561770999049x

[35] Breton F, Planté A, Legauffre C, Morel N, Adès J, Gorwood $\mathrm{P}$, et al. The executive control of attention differentiates patients with schizophrenia, their first-degree relatives and healthy controls. Neuropsychologia. 2011; 49(2):203-8 Available from: http://dx.doi.org/10.1016/j.neuropsychologia.2010.11.019

[36] Swanson JM. Role of executive function in ADHD. Journal of Clinical Psychiatry. 2003; 64(S14):35-9. PMID: 14658934

[37] Koenigs M, Grafman J. Posttraumatic Stress Disorder: The Role of Medial Prefrontal Cortex and Amygdala. Neuroscientist. 2009; 15(5):540-8. Available from: http://dx.doi. org/10.1177/1073858409333072

[38] Tan L, Zhang L, Qi R, Lu G, Li L, Liu J, et al. Brain structure in post-traumatic stress disorder: A voxel-based morphometry analysis. Neural Regeneration Research. 2013; 8(26):2405 Available from: http://dx.doi.org/10.3969/j.issn.16735374.2013.26.001 